UCRL-JC-129706

PREPRINT

\title{
Management of Unconverted Light for the National Ignition Facility Target Chamber
}

\author{
P. K. Whitman, A. K. Burnham, \\ M. Norton, F. Y. Genin, \\ J. M. Scott, W. Hibbard, \\ K. Bletzer, A. T. Anderson, \\ and S. Dixit
}

This paper was prepared for submittal to the

Third Annual International Conference on

Solid State Lasers for Application (SSLA)

to Inertial Confinement Fusion (ICF)

Monterey, California

June 7-12, 1998

July 8, 1998

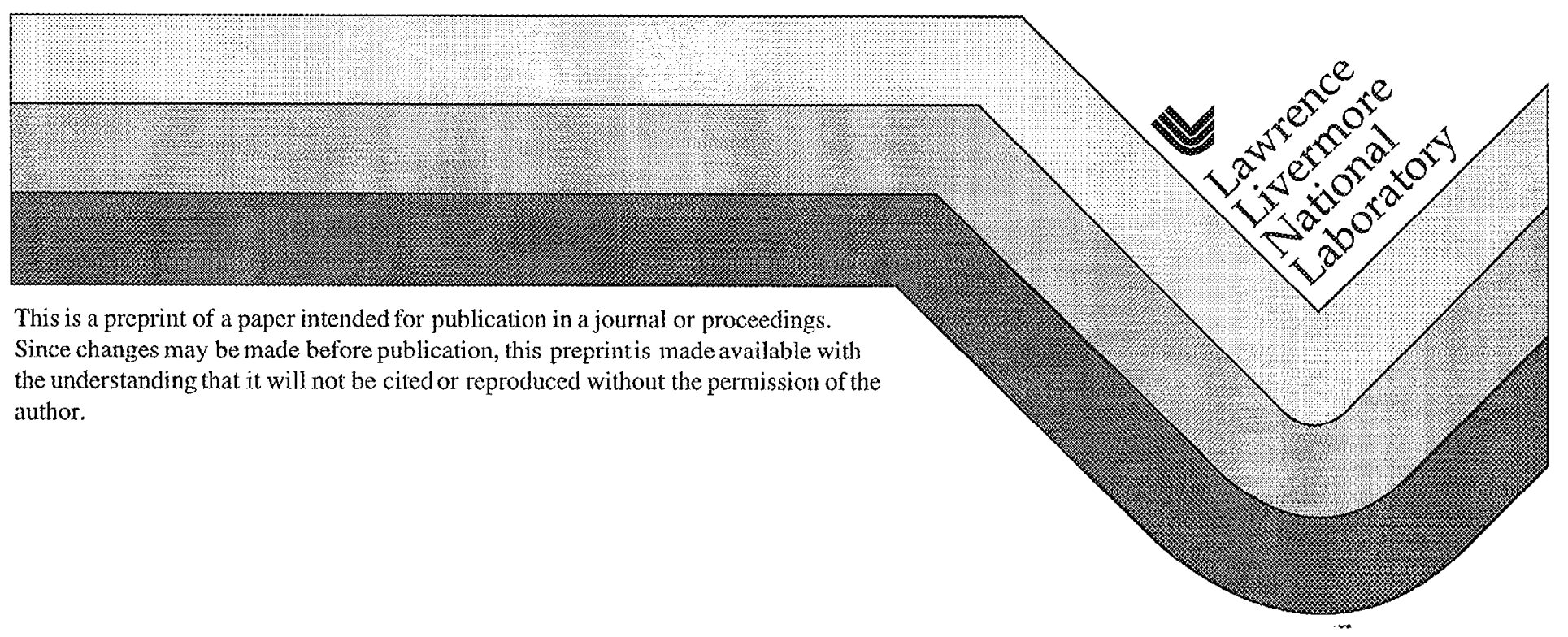




\section{DISCLAIMER}

This dncument was prepared as an account of work sponsored by an agency of the United States Government. Neither the United States Government nor the University of California nor any of their employees, makes any warranty, express or implied, or assumes any legal liability or responsibility for the accuracy, completeness, or usefulness of any information, apparatus, product, or process disclosed, or represents that its use would not infringe privately owned rights. Reference herein to any specific commercial product, process, or service by trade name, trademark, manufacturer, or otherwise, does not necessarily constitute or imply its endorsernent, recommendation, or favoring by the United States Government or the University of California. The views and opinions of authors expressed herein do not necessarily state or reflect those of the United States Government or the University of California, and shall not be used for advertising or product endorsement purposes. 


\title{
Management of unconverted light for the National Ignition Facility target chamber
}

\author{
- P. K. Whitman a , A. K. Burnham ${ }^{\mathrm{a}}$, M. Norton ${ }^{\mathrm{a}}$, F.Y. Genin", \\ J. M. Scout, W. Hibbard ${ }^{\mathrm{a}}$, K. Bletzer, A. T. Anderson", S. Dixit ${ }^{2}$ \\ ${ }^{a}$ Lawrence Livermore National Laboratory, Livermore, CA 94551 \\ 'University of California, Berkeley, CA 94720
}

\begin{abstract}
The NIF target chamber beam dumps must survive high $x$-ray, laser, ion, and shrapnel exposures without excessive generation of vapors or particulate that will contaminate the final optics debris shields, thereby making the debris shields susceptible to subsequent laser damage. The beam dumps also must be compatible with attaining and maintaining the required target chamber vacuum and must not activate significantly under high neutron fluxes. Finally, they must be developed, fabricated, and maintained for a reasonable cost. The primary challenge for the beam dump is to survive up to $20 \mathrm{~J} / \mathrm{cm}^{2}$ of $1 \mu \mathrm{m}$ light and $1-2 \mathrm{~J} / \mathrm{cm}^{2}$ of nominally $200-350 \mathrm{eV}$ blackbody temperature $x$ rays. Additional threats include target shrapnel, and other contamination issues. Designs which have been evaluated include louvered hot-pressed boron carbide $\left(B_{4} C\right)$ or stainless steel $(S S)$ panels, in some cases covered with transparent Teflon film, and various combinations of inexpensive low thermal expansion glasses backed by inexpensive absorbing glass.

Louvered designs can recondense a significant amount of ablated matcrial that would otherwise escape into the target chamber. Transparent Teflon was evaluated as an alternative way to capture ablated material. The thin Teflon sheet would need to be replaced after each shot since it exhibits both laser damage and considerable $\mathrm{x}$ ray ablation with each shot. Uncontaminated $\mathrm{B}_{4} \mathrm{C}, \mathrm{SS}$, and low thermal expansion glasses have reasonably small $x$-ray and laser ablation rates, although the glasses begin to fail catastrophically after 100 high fluencc shots. Commercially available absorbing glasses require a pre-shield of either Teflon or low thermal expansion glass to prevent serious degradation by the $x$-ray fluence.

Advantages of the hot-pressed $\mathrm{B}_{4} \mathrm{C}$ and $\mathrm{SS}$ over glass are their performance against microshrapnel, their relative indifference to contamination, and their ability to be refurbished by aggressive cleaning using $\mathrm{CO}_{2}$ pellets, glass beads, high pressure water or ultrasonic tanks. In addition the expected replacement rate to avoid catastrophic failure makes the glass option more costly. SS is less expensive, more easily formed into a louver design with high capture efficiency, and otherwise equivalent to $\mathrm{B}_{4} \mathrm{C}$. Hence, it would be preferred as long as debris shield damage is not substantially greater for SS as compared to damage from an equivalent mass of contamination of $\mathrm{B}_{4} \mathrm{C}$. If debris shield damage is problematic, the escape of SS could be mitigated by use of a transparent Teflon film. The Teflon film would require increased target chamber pumping and cleaning capability to accommodate the $x$-ray decomposition products from ablated polymer.
\end{abstract}

Keywords: laser beam dumps, National Ignition Facility, laser ablation, laser damage, $x$-ray ablation, absorbing glass, boron carbide, 409 stainless steel

\section{INTRODUCTION}

The function of a NIF target chamber beam dump is to prevent collateral damage to the laser optics by the unconverted $1 \mu \mathrm{m}$ and $0.5 \mu \mathrm{m}$ light which impinges on the target chamber wall. At the NIF design target of $83.5 \%$ peak power conversion, only $60 \%$ of the total energy is converted to $351-\mathrm{nm}$ light which can be focused on the target $^{1}$. Most of the remaining energy will be diverted around the target and target shields and fall on the beam dumps on the opposing chamber wall. Hence, a NIF shot which focuses $1.8 \mathrm{MJ}$ of $351-\mathrm{nm}$ light on the target will produce approximately $1.2 \mathrm{MJ}$ of unconverted light which must be absorbed or scattered without producing excessive contamination ${ }^{2}$. Computations utilizing the current NIF color separation grating and beam smoothing 
diffractive optic designs have predicted that the target chamber beam dumps will see peak fluences of $60-80$ $\mathrm{J} / \mathrm{cm}^{2}$ of combined 1 and $0.5 \mu \mathrm{m}$ light. These fluences greatly exceed the laser damage threshold for the current Nova target chamber beam dumps, which are comprised of a fused silica shield backed by a neutral density optical absorbing glass.

In addition to high laser light fluences, these beam dumps will routinely be exposed to $0.25-1 \mathrm{~J} / \mathrm{cm}^{2}$ of soft $x$ rays and could see as much as $2 \mathrm{~J} / \mathrm{cm}^{2}$ of higher temperature $\mathrm{x}$ rays for a $20 \mathrm{~kJ}$ yield shot ${ }^{3}$. They will also be exposed to shrapnel with momentum sufficient to generate $\mathrm{mm}$-size damage craters in brittle materials ${ }^{4}$, and significant metallic and non-metallic contamination from target debris and $\mathrm{x}$-ray ablation of the target chamber first wall ${ }^{5}$. Fused silica begins to ablate at approximately $0.5 \mathrm{~J} / \mathrm{cm}^{2}$, nominally $220-\mathrm{eV}$ blackbody temperature $\mathrm{x}$ rays ${ }^{6}$. Its laser damage threshold is severely compromised by thin layers of metal ${ }^{7}$ or absorbing particulate ${ }^{8,9}$. These factors all work together to decrease the useful lifetime and increase the likelihood of catastrophic failure of glass beam dumps such as those deployed on Nova.

Finally, the NIF target chamber beam dumps must meet demanding initial and operating cost targets. Each $1 \mathrm{~m} \times 1 \mathrm{~m}$ beam dump must cost less than $\$ 10,000$ and last for at least one year before it is removed for replacement or refurbishment. The current Nova beam dump design does not meet either of these cost targets. All of these factors prompted us to look for more robust and cost-effective designs for the hostile NIF target chamber.

Two basic beam dump designs were pursued. One concept focused on improving the traditional glass beam dump design. Less expensive commercial glasses were tested to reduce the initial cost. Scattering, low angle-of-incidence input surfaces were tested to increase the lifetime of the glass by delaying the onset of catastrophic damage. The other concept utilized the louvered 409 stainless steel (SS) or hot pressed boron carbide $\left(\mathrm{B}_{4} \mathrm{C}\right)$ designs developed for the target chamber tirst wall ${ }^{10}$, . These $\mathrm{SS}$ and $\mathrm{B}_{4} \mathrm{C}$ louvers should not suffer catastrophic failure due to contamination-induced laser damage or micro-shrapnel damage, and easily meet the NIF initial cost targets. They will, however, generate vapor and particulate which can readily damage laser optics. Initial louvered beam dump designs included a "disposable" transparent fluoropolymer film to capture the material generated by the SS or $\mathrm{B}_{4} \mathrm{C}$ louvers. The film would be replaced after every shot, and thereby accommodating contamination, modest laser damage and shrapnel penetration. Both concepts were ultimately tested at $35 \mathrm{~cm} \times 35$ $\mathrm{cm}$ aperture under NIF-like conditions. The development and testing of these concepts is the focus of this paper.

\section{SCREENING CANDIDATE MATERIALS FOR GLASS BEAM DUMPS}

Initial screening of glasses for use as NIF beam dumps focused on finding a single material that could absorb or scatter the 1.2MJ of unconverted laser light while avoiding catastrophic laser damage and also limit the total laser and $\mathrm{x}$-ray ablation from all beam dumps to less than $1 \mathrm{gm}$ per $20 \mathrm{~kJ}$ yield shot. Laser damage tests were conducted using a small beam $\left(0.1 \mathrm{~mm}^{2}\right) \mathrm{Nd}: Y A G$ laser at $1064 \mathrm{~nm}$. Damage was qualitatively assessed using Nomarski optical microscopy. Qualitative rankings of these glasses are shown in Table 1.

For absorbing glass, it was proposed that catastrophic laser damage could be avoided by limiting the surface temperature rise of the glass. Since the laser pulse is short with respect to the rate of thermal diffusion, a simple model can be used to estimate the surface temperature increase based upon the heat capacity $\left(C_{p}\right)$, density $(\rho)$, and absorption coefficient of the glass $(\alpha)$ and the pulse fluence $(F)$ at the test wavelength:

$$
\Delta \mathrm{T}=(\alpha \mathrm{F}) /\left(\rho \mathrm{C}_{\mathrm{p}}\right)
$$

Figure 1 shows the surface temperature rise as a function of input fluence and glass absorption coefficient. Architectural glasses with absorption coefficients between $1.5-3 \mathrm{~cm}^{-1}$ at $1-\mu \mathrm{m}$ were chosen to limit the surface temperature rise to less than $100^{\circ} \mathrm{C}$ at $60 \mathrm{~J} / \mathrm{cm}^{2}$. Figure 2a shows the typical 'melted surface' damage morphology which occurred at high fluence, even though the calculated surface temperature was well below the melting point of the glass. Catastrophic damage was not observed for either specular (as-received float glass) or sandblasted absorbing glasses. PPG Azurlite $\mathrm{TM}^{\mathrm{M}}$ architectural glass, a blue glass with $1-\mu \mathrm{m}$ absorption coefficient of $3.7 \mathrm{~cm}^{-1}$ was selected as the most promising material for further testing. 


\begin{tabular}{|c|c|c|c|c|c|}
\hline$\because$ & $\begin{array}{l}\text { Absorption } \\
\text { Coefficient } \\
\text { at } 1053-\mathrm{nm} \\
(\text { per } \mathrm{cm})\end{array}$ & $\begin{array}{l}\text { Specular } \\
\text { Surface } \\
\text { Laser } \\
\text { Damage } \\
\text { Performance }\end{array}$ & $\begin{array}{l}\text { Sandblasted } \\
\text { Surface Laser } \\
\text { Damage } \\
\text { Performance }\end{array}$ & $\begin{array}{l}\text { Thermal } \\
\text { Expansion } \\
\text { Coefficient } \\
\left(\times 10^{6}\right)\end{array}$ & $\begin{array}{l}\text { X-ray } \\
\text { Ablation } \\
\text { Comparison } \\
(\mathrm{FS} \approx 1)\end{array}$ \\
\hline \multicolumn{6}{|l|}{ Cheap Doped Glasses } \\
\hline PPG Azurlite ${ }^{\top M}$ & 3.7 & Good & Good & 8.6 & 10 \\
\hline PPG Solex ${ }^{T M}$ & 2.9 & OK & Good & 8.6 & 10 \\
\hline PPG Greylite ${ }^{\top M} 14$ & 1.6 & Good & Good & 8.6 & 10 \\
\hline \multicolumn{6}{|l|}{ Cheap Undoped Glasses } \\
\hline Schott Borofloat ${ }^{\mathrm{rM}}$ borosilicate & 0.1 & Fail & OK & 3.3 & 2 \\
\hline Corning Pyrex ${ }^{\mathrm{TM}}$ borosilicate & 0.1 & Fail & OK & 3.3 & 2 \\
\hline \multicolumn{6}{|l|}{ Optical Grade Glasses } \\
\hline Schott VG-10 & 0.8 & Good & Good & 11.0 & 20 \\
\hline Schott BK-7 & 0 & Fail & $\mathrm{OK}$ & 7.4 & 10 \\
\hline Schott $S-1$ & 0 & Poor & Poor & 6.0 & 3 \\
\hline Schott S-8020 & 0 & OK & OK & 3.0 & 10 \\
\hline Fused Silica (FS) & 0 & Fail & OK & 0.6 & 1 \\
\hline
\end{tabular}

Table 1: Results of small beam laser damage tests and Nova $x$-ray ablation test. Laser damage rankings are reported for 600 shots, $60 \mathrm{~J} / \mathrm{cm}^{2}, 0.8 \mathrm{~mm}$ beam, in air. Approximate $\mathrm{x}$-ray ablation rates are reported relative to the ablation rate of fused silica. Low thermal expansion materials give low $\mathrm{x}$-ray ablation (mass loss).

Commercial and optical glasses with low absorption coefficients $\left(<0.5 \mathrm{~cm}^{-1}\right)$ were also tested with either specular or diffusely scattering surfaces. Sandblasted or blanchard ground surfaces effectively scattered rather than absorbed much of the unconverted light and delayed the onset of catastrophic damage. Sandblasted samples typically failed catastrophically after $100-300$ shots, regardless of whether they were near-optical quality fused silica or inexpensive borosilicate float glass. Figure $2 b$ shows the typical 'catastrophic' damage morphology.

\section{ESTIMATION OF X-RAY ABLATION RATES}

$\mathrm{X}$-ray ablation was determined by subjecting test coupons to $\mathrm{x}$ rays generated in Nova target experiments. Initial screening experiments exposed $1 \mathrm{~cm}^{2}$ pieces to $1-4$ shots ranging from $1-3.5 \mathrm{~J} / \mathrm{cm}^{2}$. Mass ablation as a function of $\mathrm{x}$-ray fluence (distance from target) could be estimated by contact profilometry from the step height difference between a masked area and the exposed area for polished samples. Ablation rates for roughened $\mathrm{B}_{4} \mathrm{C}$, $\mathrm{Al}$, and SS surfaces were calculated from estimates of fractional areal removal and depth using either SEM and $\mathrm{AFM}^{6}$ or white light interferometry. Results of these tests for candidate beam dump materials, including $\mathrm{B}_{4} \mathrm{C}, \mathrm{SS}$, several glasses and Teflon are found in Figure 3. For sandblasted glass samples or glass samples which massively thermally crazed, the mass ablation was estimated by gravimetric methods. Since test coupons can both gain and lose significant mass due to target shrapnel and this effect can be of similar magnitude to the estimated $x$-ray ablation loss, only qualitative results arc reported in Table 1 for candidate glasses.

As seen in Table 1, $\mathrm{x}$-ray ablation is strongly correlated to the thermomechanical properties of the glass. Fused silica and borosilicate, the glasses with the lowest thermal expansion have the lowest ablation rates. Sodalime glasses, which include all the 'absorbing' architectural glasses, have approximatcly ten times the fused silica $x$-ray ablation rate due to thermal crazing and macroscopic scaling of the surfaces. These thermally crazed surfaces would be expected to damage further upon subjection to high laser fluence, exceeding the damage ratc one would estimate by summing the separately achieved $x$-ray and laser ablation rates. We did not, however, test this expectation. Instead, we chose to pursue a glass 'sandwich' design where the first layer would be an $x$-ray absorption layer of sandblasted low thermal expansion glass and the second layer would absorb the transmitted unconverted light to prevent laser ablation of the target chamber wall. Borosilicate and non-optical grade fused silica were chosen for the $\mathrm{x}$-ray absorption layer. PPG Azurlite architectural glass, a blue glass with 1-mm absorption coefficient of $3.7 \mathrm{~cm}^{-1}$ was selected as the $1-\mathrm{mm}$ absorbing glass for further testing. 
A second series of experiments was conducted to better characterize the material response of the best glasses to the $x$-ray and shrapnel threat. A set of eight $2.5 \mathrm{~cm} \times 5 \mathrm{~cm}$ coupons of fused silica and borosilicate glass were exposed to a total of 83 Nova shots over a six-week period. A portion of the sample was polished to $0.1 \mathrm{~mm}$ finish. The remainder of the sample was bead blasted. The total amount of material removed was determined by weighing the samples before and after exposure. The amount of material removal due to $\mathrm{x}$ rays was calculated from the profilometry on the polished surface. The amount of material removal attributed to shrapnel was estimated by difference. Scaling the results from Nova conditions to the expected NIF parameters predicts that the expected mass loss from shrapnel damage is approximately $0.25-1.7 \mathrm{~g} / \mathrm{shot}$ summed over all beam dumps while the expected loss from $\mathrm{x}$-ray ablation is $0.5-1.0 \mathrm{~g} / \mathrm{shot}$. For a louvered glass design, approximately $50 \%$ of the $\mathrm{x}$ ray ablated material would be captured by the back side of adjacent louvers, while the shrapnel-initiated debris are unlikely to have high enough velocity to implant themselves. These tests suggest that the sensitivity of glass to target shrapnel is a distinct disadvantage of glass beam dumps.

\section{ESTIMATION OF LASER ABLATION RATES}

Mass generation curves as a function of fluence were generated for the candidate materials using the Advanced Glass High Average Power (AGHAP) laser at LLNL. Experiments were run in vacuum at $10^{-5}$ torr using a $3 \mathrm{~mm} \times 4 \mathrm{~mm}$ beam. The 1053-nm, 14-ns FWHM Gaussian beam was pulsed at $0.1 \mathrm{~Hz}$ for the glass samples - a compromise between introducing non-representative thermal effects in the absorbing glass and completing the experiments within a reasonable timeframe. All of the candidate glass materials were tested at normal incidence, both as individual pieces and in the proposed 'sandwich' configuration. SS and boron carbide samples were tested at $1 \mathrm{~Hz}$ rep rate and $60^{\circ}$ angle of incidence. Each sample was weighed before and after subjecting it to either 100 or 500 shots.

Figure 4 summarizes the observed mass loss data as if the damage rate was constant for all shots. This appears to be a good assumption for the SS, $\mathrm{B}_{4} \mathrm{C}$, and the Azurlite absorbing glass which never damaged catastrophically. The mass of SS and $\mathrm{B}_{4} \mathrm{C}$ ablated per shot rises sharply until approxirnately $10 \mathrm{~J} / \mathrm{cm}^{2}$, then plateaus. Thus $\mathrm{SS}$ and $\mathrm{B}_{4} \mathrm{C}$ are relatively insensitive to the amplitude and size of "hot spots" in the laser beam predicted by various assumptions of beam modulation. The Azurlite ablation rate increases exponentially throughout the test range. For the fused silica and borosilicate glass, catastrophic damage occurred somewhat unpredictably, generally between 100 and 500 shots, making the estimation of mass generation less certain. The curves in Figure 4 use the lower mass generation rates estimated from 100 shots. Sandwiches of fused silica and Azurlite did not noticeably reduce the damage to the fused silica input surface, but thcy did climinate ablation from the Azurlite surface at even the highest fluence.

An additional set of tests was conducted on sandblasted fused silica to evaluate the potential for a louvered glass beam dump design. In this design, the fused silica louvers would be mounted at $45-60^{\circ}$ angle of incidence while the absorbing glass would remain normal to the beam. As seen in Figure 5 , the higher angle of incidence may delay the onset of catastrophic damage, but the data is too sparse and scattered to draw firm conclusions. In this configuration, the edges of the sample which faced the beam always damaged extensively. This is a primary concern for louvered glass beam dumps.

\section{CALCULATION OF ABlation RATES FOR A 1.8 MJ NIF PULSE}

In order to compare the performance of the various beam dump concepts under NIF operating conditions, we needed to know the areal fluence distribution on the beam dumps. The calculation initiates from the Prop-92 $2^{12}$ beam profile exiting the final focus lens. This bearn is propagated through a $381-\mu \mathrm{m}$ period split full aperture color separation grating and either the discrete 16-level mod- $2 \pi$ kineform phase plate (KPP) or a continuous contour plate (CPP) to the beam dump on the opposing wall. Figure 6 shows the area as a function of fluence for one of the 48 beam dumps in the NIF target chamber. The total mass which would be generated by one beam dump for a single $1.8 \mathrm{MJ}$ shot can be calculated from the linear sum of the product of the mass generation depicted in Figure 4 with the areal fluence distribution shown in Figure 6.

Table 2 shows the total mass of material which will be generated by laser and $x$-ray ablation for all 48 beam dumps for a single $1.8 \mathrm{MJ}$ shot. The total contamination which will be introduced into the target chamber is 
estimated by combining the predicted capture efficiency of the various louver designs with the measured laser, $\mathrm{x}$ ray and shrapnel generation terms. X-ray ablation is calculated for $1 \mathrm{~J} / \mathrm{cm}^{2}$. The dog-legged SS louver design is predicted to capture $9.9 \%$ of the generated contamination, while the less efficient glass and $\mathrm{B}_{4} \mathrm{C}$ louver designs are predicted to capture only $50 \%$ of the ablated material. It should be noted that the small areas of high laser fluence which are created by the KPP modulation do not significantly impact the $\mathrm{B}_{4} \mathrm{C}$ and SS designs because they are relatively insensitive to fluence above $25 \mathrm{~J} / \mathrm{cm}^{2}$. The estimates for the borosilicate and fused silica beam dumps assume that these materials will be limited to a few hundred shots to avoid catastrophic damage and exponential increases in mass generation. Only the Azurlite glass produced less laser-ablated material per shot than the SS. However, the Azurlite x-ray ablation and thermal crazing limits this material to applications with either the fused silica or borosilicate glass shield.

\begin{tabular}{|c|c|c|c|c|c|}
\hline \multirow[b]{2}{*}{ Material } & \multicolumn{4}{|c|}{ Mass Generation Terms } & \multirow{2}{*}{$\begin{array}{l}\text { Target Chamber } \\
\text { Contamination Rate } \\
\text { g/shot }\end{array}$} \\
\hline & $\begin{array}{r}\text { Las } \\
\mathrm{kpp} g / \mathrm{sho}\end{array}$ & $\begin{array}{l}\text { blation } \\
\text { cpp g/shot }\end{array}$ & $\begin{array}{l}\text { X-ray } \\
\text { g/shot }\end{array}$ & $\begin{array}{c}\text { Shrapnel } \\
\text { g/shot }\end{array}$ & \\
\hline $\mathrm{B}_{4} \mathrm{C}$ & 1.4 & 1.4 & 0.2 & $\sim 0$ & 0.8 \\
\hline Stainless steel $*$ & 1.0 & 1.0 & 10.0 & $\sim 0$ & 1.1 \\
\hline Azurlite $^{T M}$ & 0.6 & 0.5 & $\sim 11$ & 1 & 6.8 \\
\hline Borosilicate & $0.8 * * *$ & $0.6 * * *$ & 2.2 & 1 & 2.5 \\
\hline Fused silica** & $2.2 * * *$ & $1.6 * * *$ & 1.1 & 1 & 2.7 \\
\hline
\end{tabular}

Table 2: Mass generation terms predicted for NIF beam dumps using the test materials and no louvers for 1.8MJ blue light focused on target and $1 \mathrm{~J} / \mathrm{cm}^{2} \mathrm{x}$-ray fluence. * Louvers can capture $\sim 90 \%$ of the SS, $\sim 50 \%$ of theB ${ }_{4} \mathrm{C}$ and glass ablation. **Fused silica is limited to a few hundred shots. *** Glass numbers are highly variable.

\section{TESTING 1/2 SCALE NIF BEAM DUMP PROTOTYPES}

The test conditions on Nova's 2-beam target chamber were comparable to those expected on NIF. For 2 beam tests, we utilized a 1-mm Gaussian pulse, $8-10 \mathrm{~ns} H W F M$, average fluence up to $15 \mathrm{~J} / \mathrm{cm}^{2}$, modulation over small areas to $45-60 \mathrm{~J} / \mathrm{cm}^{2}$. The best approximation of the NIF target chamber beam dump application is a $17 \mathrm{~ns}$ square pulse, average fluence up to $20 \mathrm{~J} / \mathrm{cm}^{2}$ over significant areas and modulation up to $60-80 \mathrm{~J} / \mathrm{cm}^{2}$. (The $17 \mathrm{~ns}$ pulse approximation results from the poor conversion which takes place during the long 'foot' of the NIF baseline pulse.) The 2-beam target chamber was maintained at approximately $10^{-6}$ torr and the repetition rate of up to 1 shot per $1.5-2$ hours closely approximates the NIF goal of 1 shot per 4 hours.

Three prototypes were prepared for testing on the 2-Beam arm of the Nova laser. Each prototype had four $17 \mathrm{~cm} \times 35 \mathrm{~cm}$ louvers held at $60^{\circ}$ incidence to the beam inside an aluminum box as shown in Figure 7 . One prototype had four 304 SS louvers with a transparent fluoropolymer (FEP) witness film stretched across the clear aperture to collect any ablated SS which was not captured by the louvers or walls of the box. A second prototype substituted four hot pressed $B_{4} C$ panels for the SS louvers. The third prototype substituted four $10 \mathrm{~mm}$ thick panels of sandblasted fused silica for the SS, had no witness film, and added an absorbing glass layer.

The 2-beam laser configuration allowed us to inspect the beam dump for macroscopic damage and retrieve and replace the fluoropolymer film after each shot. Diagnostics were monitored to ensure that the phaseconjugated back-reflection remained below the detection limit. The target chamber pressure was monitored at the cryopump port to detect vapor generation as a result of laser ablation. In addition, a residual gas analyser (RGA) was installed on the target chamber for the SS prototype runs to record and identify the atomic mass units (AMU) of vapor phase contaminants. Finally, glass slide and $\mathrm{KBr}$ pellet witness samples were placed in the beam dump box and in the 2-beam vacuum vessel to sample the particulate which was generated and not captured by either the fluoropolymer witness sheet or the beam dump louvers.

Figure 7 shows the beam dump test box setup with the SS louvers after the final $8.8 \mathrm{~kJ}$ shot. The pattern that is etched into the SS is from the KDP conversion crystal array 'eggcrate'. The light areas forming a crosshatched pattern with a split circle in the center within the circular beam fooprint are the areas where the beam is blocked. This pattern was clearly visible after the first low fluence shot at $3.5 \mathrm{~kJ}$ and was enhanced with each 
succeeding shot. A similar image of the KDP eggcrate was observed on the $\mathrm{B}_{4} \mathrm{C}$ louvers at the same fluence level. In the third prototype containing the fused silica louvers there was a $6 \mathrm{~mm} \times 35 \mathrm{~mm} \times 35 \mathrm{~mm}$ piece of sandblasted blue Azurlite glass behind the fused silica louvers to prevent transmitted light from reaching the aluminum back plane of the test box. Testing of this prototype was aborted when the transmitted light from a single $3.5 \mathrm{~kJ}$ pulse ablated aluminum from the mounting plates onto the output surface of the fused silica forming a black image of the beam footprint. Clearly we had the absorbing glass in the wrong location and there was no point in continued testing.

Transmittance of the FEP films from the $\mathrm{B}_{4} \mathrm{C}$ and $\mathrm{SS}$ louver tests were scanned at 1055,526 , and $351 \mathrm{~nm}$ on our photometer. The 'KDP eggcrate' pattern was clearly visible on the films removed from the two highest fluence SS louver tests. They were not visible on the films from the lower fluence SS tests nor on the films from any of the $\mathrm{B}_{4} \mathrm{C}$ tests. $\mathrm{X}$-ray fluorescence (XRF) mapping of the chrome, nickel, and iron distribution on these films revealed that the SS contamination was not correlated to location inside and outside the beam footprint. When hydrochloric acid was utilized to dissolve the SS from selected areas of the film it was found that the transmittance loss due entirely to SS contamination was approximately $1 \%$. Inside the beam footprint, where the FEP laser damage created scatter loss which was enhanced by the SS contamination, there was a $6 \%$ drop in transmittance before $\mathrm{HCl}$ cleaning and a residual $3.2 \%$ loss due to laser damage after the SS was removed. Figure 8 shows the $\mathrm{XRF}$ map of the fluoropolymer witness film after an $8.8 \mathrm{~kJ}$ test of the SS louvers. Figure $9 \mathrm{a}$ shows the corresponding 1055 nm transuitlance map of this same witness film.

\begin{tabular}{lccc}
\hline Fluence $\left(\mathrm{J} / \mathrm{cm}^{2}\right)$ & $\begin{array}{l}\mu \mathrm{g} / \mathrm{cm}^{2} \text { total expected } \\
\text { mass generation }\end{array}$ & $\begin{array}{l}\mu \mathrm{g} / \mathrm{cm}^{2} \text { captured on } \\
\text { FEP }\end{array}$ & $\begin{array}{l}\text { Calculated } \\
\text { capture efficiency }\end{array}$ \\
\hline Sum of 1 shot each at 5,7, & 40.5 & $3.6-18.3$ range & $54-91 \%$ \\
and $11 \mathrm{~J} / \mathrm{cm}^{2}$ & & 9.2 average & avg: $77 \%$ \\
1 shot at $14 \mathrm{~J} / \mathrm{cm}^{2}$ & 19.5 & $3.7-11.8$ range & $39-81 \%$ \\
& 19 & 7.6 average & avg: $61 \%$ \\
1 shot at $12 \mathrm{~J} / \mathrm{cm}^{2}$ & & $2.2-7.8$ range & $59-88 \%$ \\
& & 5.5 average & avg: $71 \%$ \\
\hline
\end{tabular}

Table 3: Estimation of the Nova 2-beam design SS louver capture efficiency based upon predicted laser ablation generation rates and measured iron distribution captured on the FEP witness film.

Figure $9 \mathrm{~b}$ summarizes the transmittance loss inside and outside the 'eggcrate' as a function of fluence incident on the SS louvers. One can see that the transmittance loss outside the beam is essentially independent of fluence, as would be expected from the AGHAP laser ablation tests. Table 3 summarizes the XRF results from mapping the three FEP films used in the SS louver experiments. The roughness of the SS prevented direct measurement of the ablation step height on the louvers. However, one can calculate the expected SS generation rate from the AGHAP laser ablation curves, the measured average fluence and an assumed 3:1 modulation over 5\% of the surface. If one also assumes that the FEP film captured essentially all of the SS which escaped capture by the SS louvers, then one can estinate the louver capture efficiency. These estimates, which range from $61 \%-77 \%$ are slightly higher than the theoretical capture efficiency of $60 \%$ for the tested design.

The pressure measured at the cryopump indicated that there was a slight increase in pressure due to the damage of the fluoropolymer film at all fluences. The magnitude of this pressure pulse was independent of fluence and louver material. RGA analyses during the SS louver tests measured a slight upward trend in the partial pressure of $\mathrm{AMU} 50,69$, and 100 with increasing fluence which is consistent with $\mathrm{CF}_{2}, \mathrm{CF}_{3}$, and $\mathrm{C}_{2} \mathrm{~F}_{4}$ decomposition products which would be generated by the FEP fluoropolymer film.

Of greater concern was the 3 order of magnitude pressure increase which occurred when the $\mathrm{B}_{4} \mathrm{C}$ louvers were subjected to $12 \mathrm{~J} / \mathrm{cm}^{2}$ average fluence. The target chamber had a distinctly pungent smell, similar to fresh asphalt after each test of the $\mathrm{B}_{4} \mathrm{C}$ louvers and most strongly after this final high fluence shot. It is not known how much of the pressure pulse was due to laser cleaning which would decrease after the first few high flucnce shots and how much was due to vaporization of the $\mathrm{B}_{4} \mathrm{C}$ itself. If $100 \%$ of the predicted laser ablated $\mathrm{B}_{4} \mathrm{C}$ was vaporized it would produce the observed pressure pulse. The observation of condensed plasticizers (phthalates) on the 
interior surface of the fluoropolymer witness sheet from the highest fluence shot suggest that contamination of the $\mathrm{B}_{4} \mathrm{C}$ played a role in the observed pressure pulse.

\section{SUMMARY AND FUTURE TESTS}

The Nova 2-beam experiments $\left(1000 \mathrm{~cm}^{2}\right)$ were consistent with our mass generation predictions from the smaller beam $\left(0.2 \mathrm{~cm}^{2}\right)$ experiments and the calculated louver capture efficiency. This gives us added confidence in the SS louver design in the face of limited large scale testing opportunities. The differences between the $\mathrm{B}_{4} \mathrm{C}$ and SS behavior - both in pressure pulse and forward projected contamination (FEP transmittance loss) were not predicted by the small scale experiments. In order to better quantify the mass generation and contamination potential for SS louvers, we are currently monitoring a multi-week test of an improved SS louver design in the Nova 10-beam target chamber. This "dog-leg" design is calculated to provide $90 \%$ capture efficiency vs. the $60 \%$ capture efficiency predicted for the earlier design. This SS louvered beam dump replaces one of Nova's target chamber beam dumps. Polished titanium strips have been attached to the backside of a louver in order to directly measure the captured SS mass and polished SS strips have been attached to the facing louver to directly measure the ablation generation term. Pieces of titanium have also been placed in front of the beam dump to measure the

amount which escapes from the louver. We have also strategically placed some high damage threshold fused silica samples in the Nova 10-beam chamber to collect ablated material for off-line measurement of the impact of this contamination on fused silica optic damage threshold.

\section{CONCLUSIONS}

The glass options are the least preferred solution for NIF target chamber beam dumps. The fused silica and borosilicate glasses present a high risk of catastrophic failure due to impact or laser damage. While the absorbing glass appears to have lower risk of catastrophic failure due to laser damage alone, the commercially available soda-lime glasses have poor $\mathrm{x}$-ray resistance and will still be susceptible to impact damage. A more costly solution might be to develop a low thermal expansion absorbing glass, but even this option will still have high maintenance costs and tisk of catastrophic failure due to contamination and the impact of target shrapnel.

$\mathrm{B}_{4} \mathrm{C}$ has low $\mathrm{x}$-ray and laser ablation mass generation rates and good mechanical impact resistance. However, the cost for high purity hot pressed $\mathrm{B}_{4} \mathrm{C}$ in a louver configuration will exceed the NIF cost criteria. Identification of the source of the pressure spikes and 'burnt rubber' smell observed during the 2-beam experiment is needed before implementing this approach. Overall, $\mathrm{B}_{4} \mathrm{C}$ demonstrated no advantage over 409 SS louvers.

SS louvers are the best option to meet both the NIF cost and performance goals. SS louvers have both the lowest initial cost and the lowest predicted maintenance cost of the three options tested. Since SS can be manufactured into the most effective louver designs it will introduce the lowest mass of contamination into the target chamber. Finally, SS has the lowest risk of catastrophic failure. The concern that remains to be addressed is the threat of damage threshold reduction of laser optics from SS contamination as compared to $\mathrm{B}_{4} \mathrm{C}$ or absorbing glass contamination.

\section{ACKNOWLEDGMENTS}

This work was performed under the auspices of the U. S. Department of Energy by Lawrence Livermore National Laboratory under Contract No. W-7405-ENG-48. 


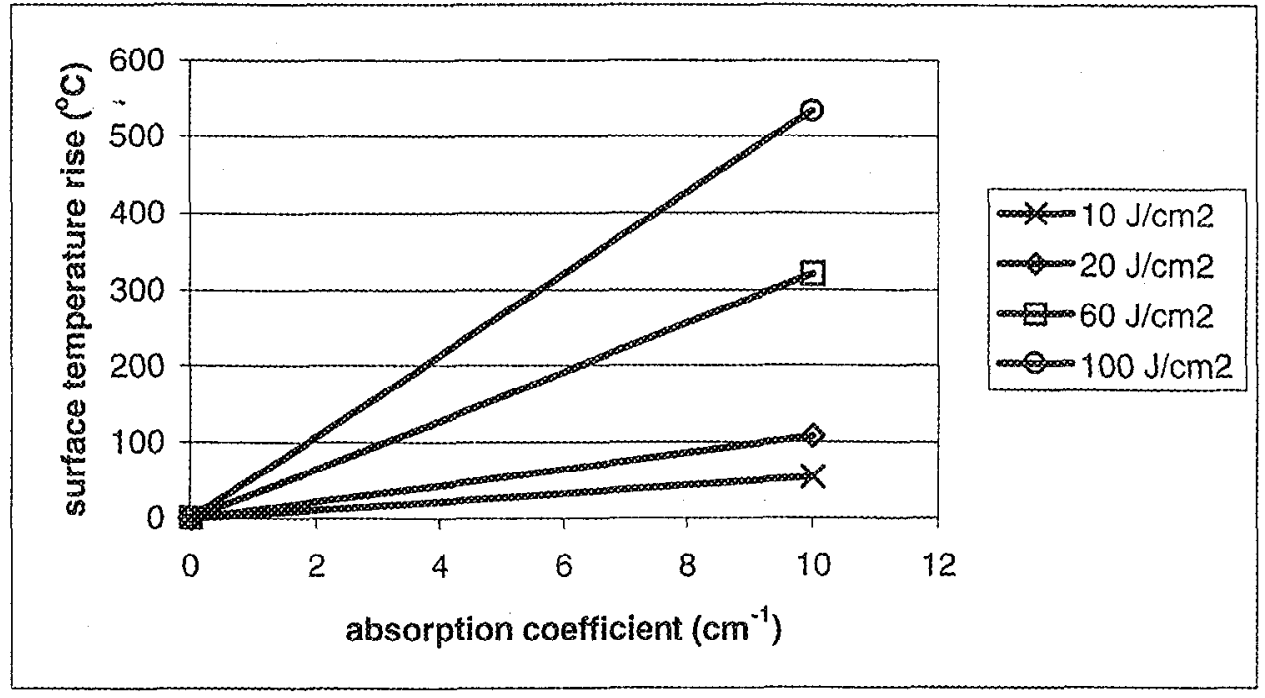

Figure 1: Surface temperature increase as a function of the absorption coefficient of the glass after a single pulse at $10,20,50$ or $100 \mathrm{~J} / \mathrm{cm}^{2}$. Calculations assume constant glass density of $2.5 \mathrm{~g} / \mathrm{cm}^{3}$ and heat capacity of $0.75 \mathrm{~J} / \mathrm{g}-{ }^{\circ} \mathrm{K}$.
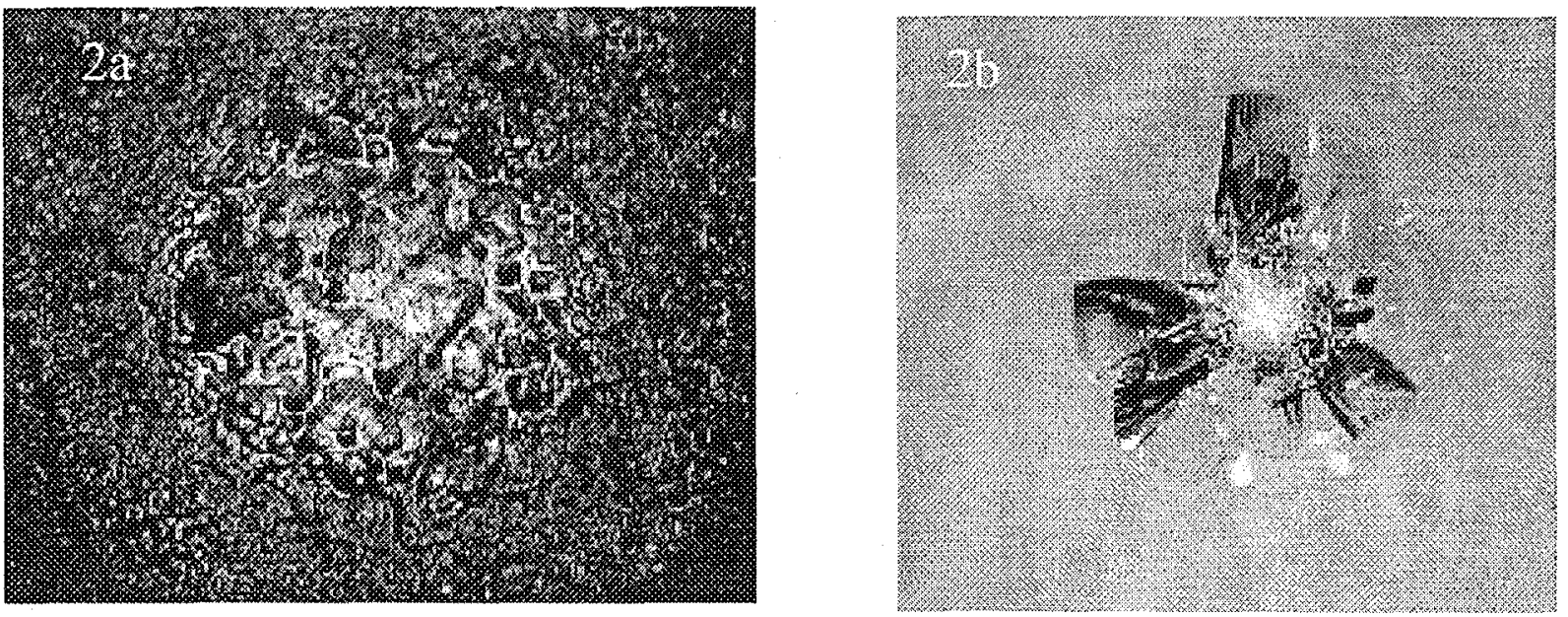

Figure 2: Characteristic damage morphologies for a) sandblasted PPG Azurlite (absorbing) architectural glass and b) as-received Schot Borofloat (low absorption) borosilicate glass. Each damage site received 300 shots at $60 \mathrm{~J} / \mathrm{cm}^{2}, 7.5-\mathrm{ns}, 10 \mathrm{~Hz}, 1064-\mathrm{nm}$. Notice that the surface of the absorbing glass melted, but did not fracture. The borosilicate glass damage drilled through the bulk from the output surface. 


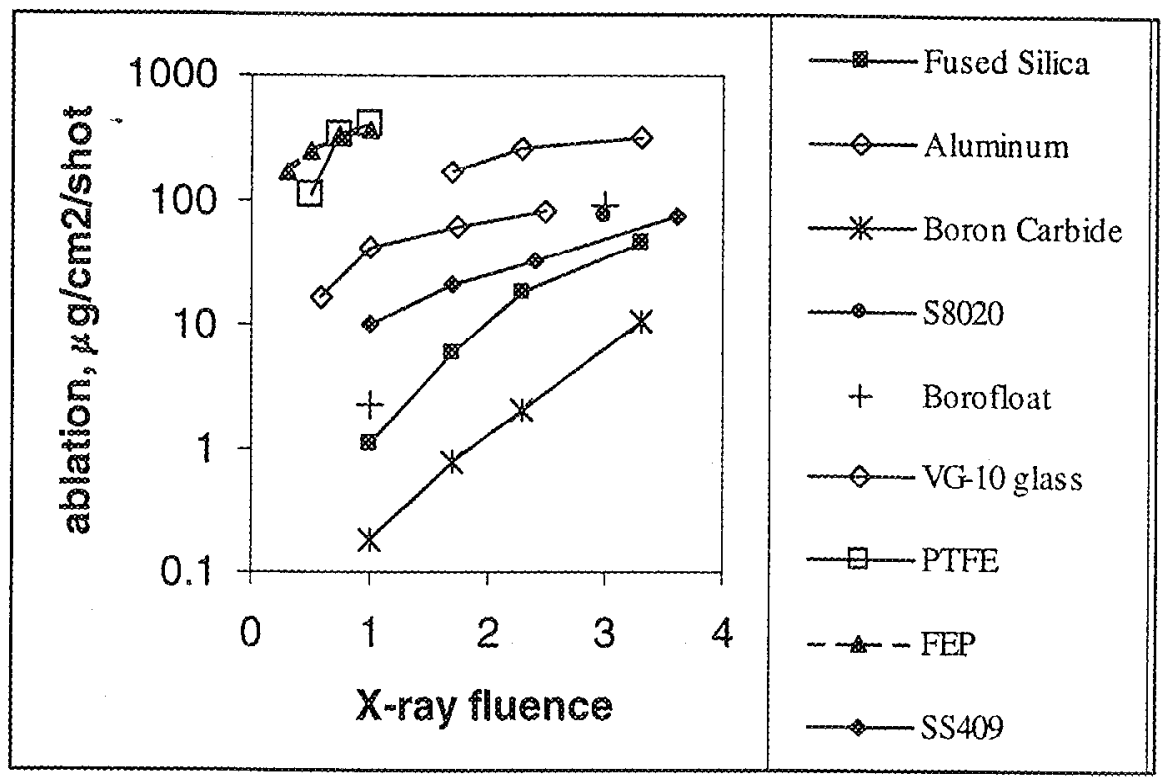

Figure 3: Ablation of hot pressed $\mathrm{B}_{4} \mathrm{C}, 409$ SS, DuPont FEP, PTFE, Schott VG-10, Schott Borofloat and S8020 borosilicates, and fused silica as a function of $\mathrm{x}$-ray fluence. Samples were exposed to 1 to 4 shots in the Nova target chamber.

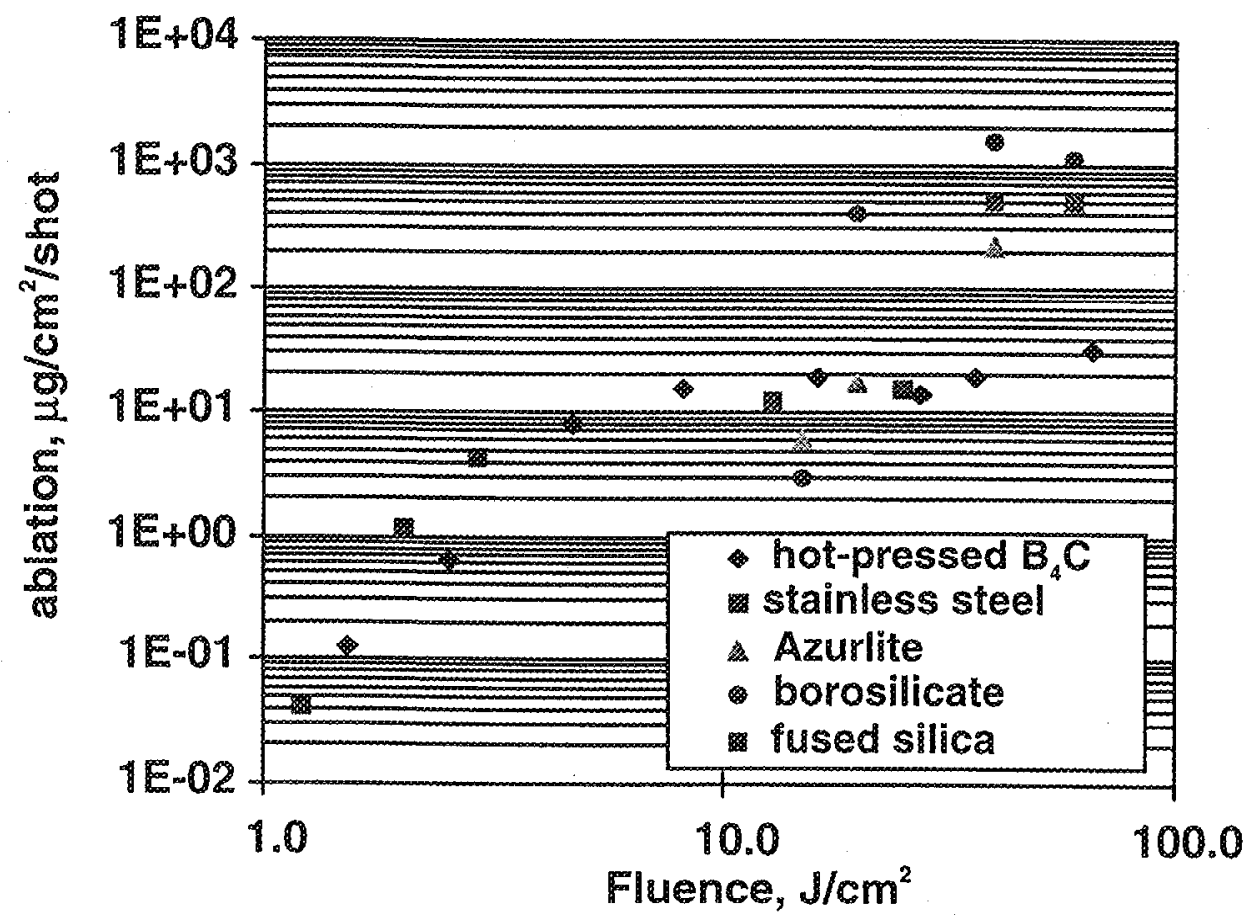

Figure 4: Laser ablation of $\mathrm{B}_{4} \mathrm{C}, 304 \mathrm{SS}$, PPG Azurlite ${ }^{\mathrm{TM}}$ blue architectural glass, borosilicate glass, and fused silica as a function of fluence at 1053-nm, 14-ns FWHM. Glass samples were measured at normal incidence, $0.1 \mathrm{~Hz}$ repetition rate and had sandblasted surfaces. $\mathrm{B}_{4} \mathrm{C}$ and SS were measured at $60^{\circ} \mathrm{AOI}, 1 \mathrm{~Hz}$. All data are average for 500 shots, except as noted. Borosilicate and fused silica ablation rates are calculated from 100 shots. 

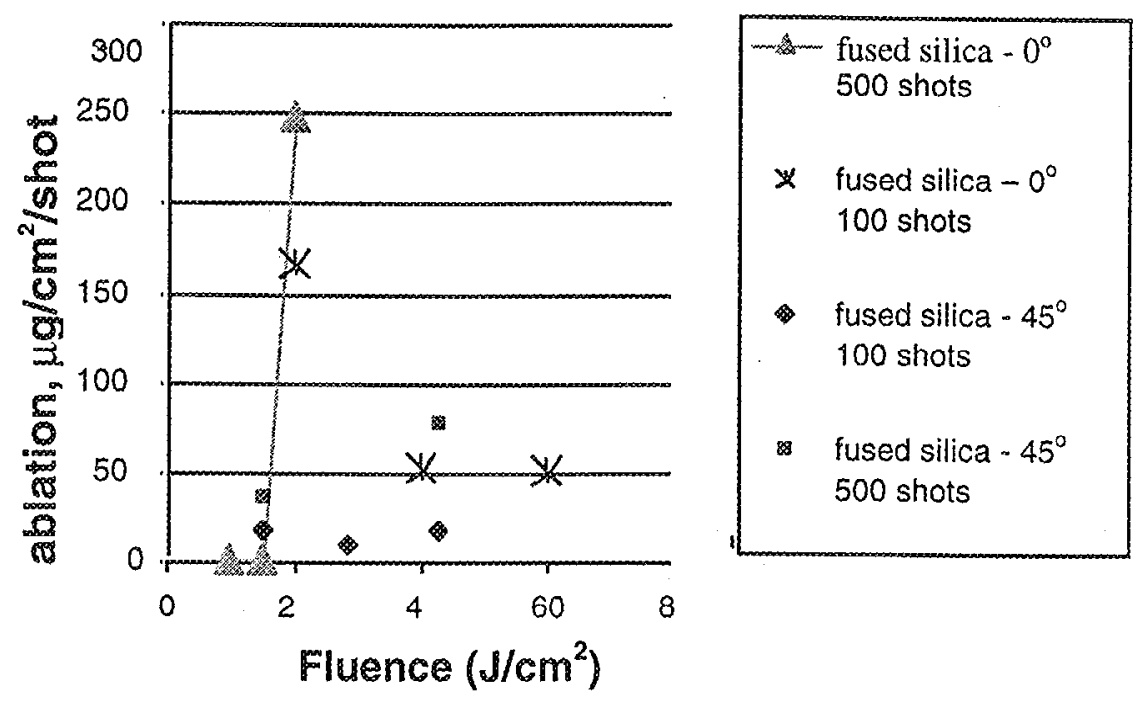

Figure 5: Ablation of sandblasted fused silica as a function of angle of incidence and fluence at 1053-nm, 14ns FWHM, $0.1 \mathrm{~Hz}$ repetition rate.

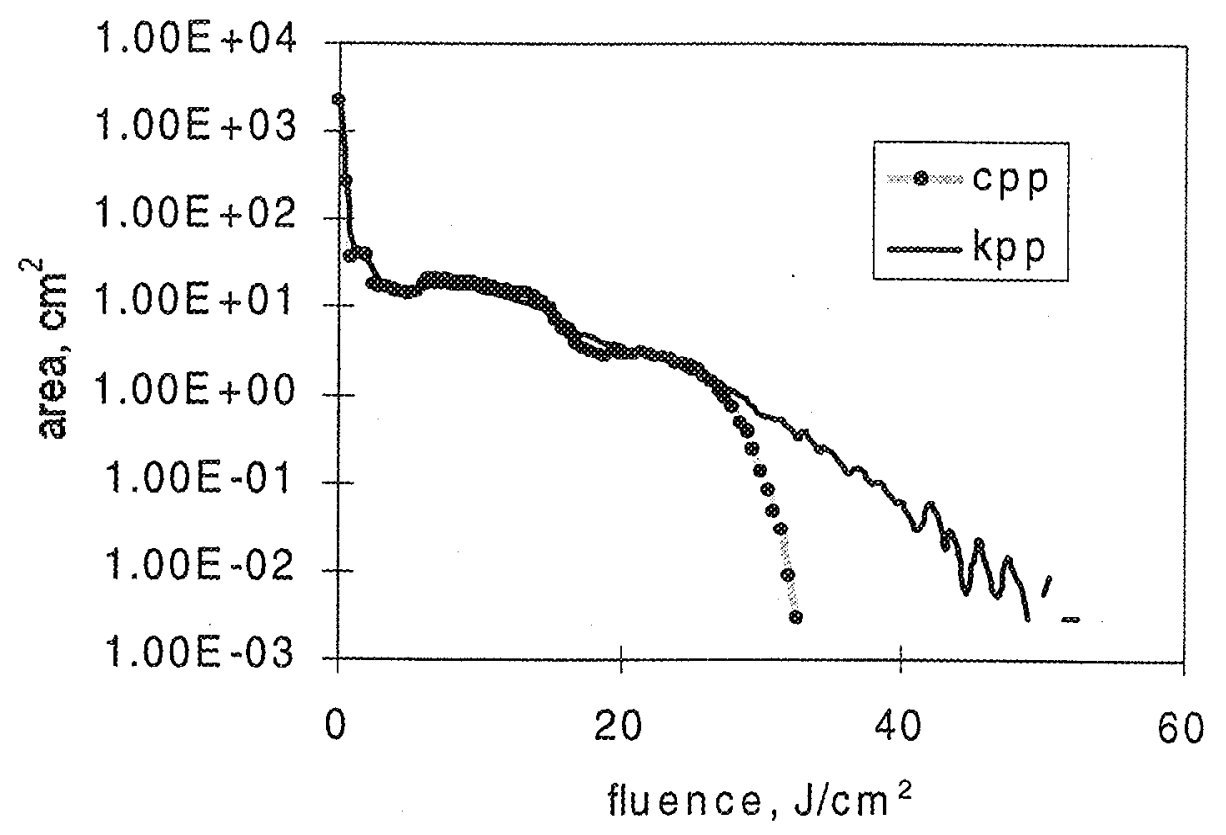

Figure 6: Computed areal distribution of fluence absorbed by one NIF beam dump. The continuous phase plate (CPP) produces a narrower distribution. Modulation introduced by the kineform phase plate (KPP) extends the 'tail' of the distribution to higher fluences. 


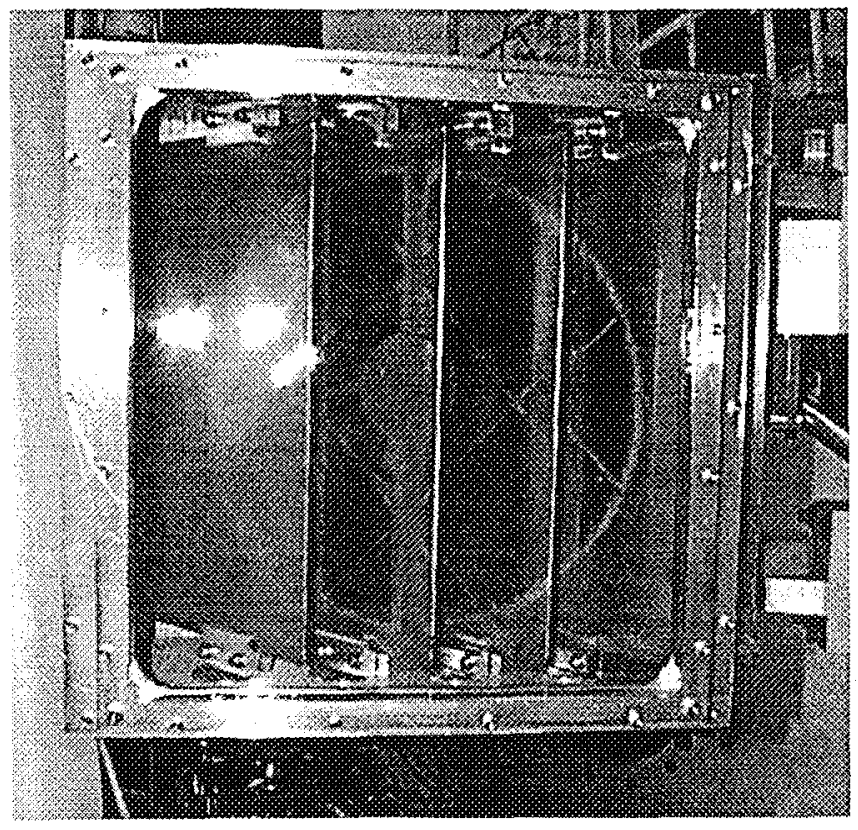

Figure 7: The 1/2-scale NIF beam dump prototype configured with 304 SS louvers and a transparent fluoropolymer film stretched across the input aperture. Photographed after the final shot at $8.8 \mathrm{k} J$ shot.

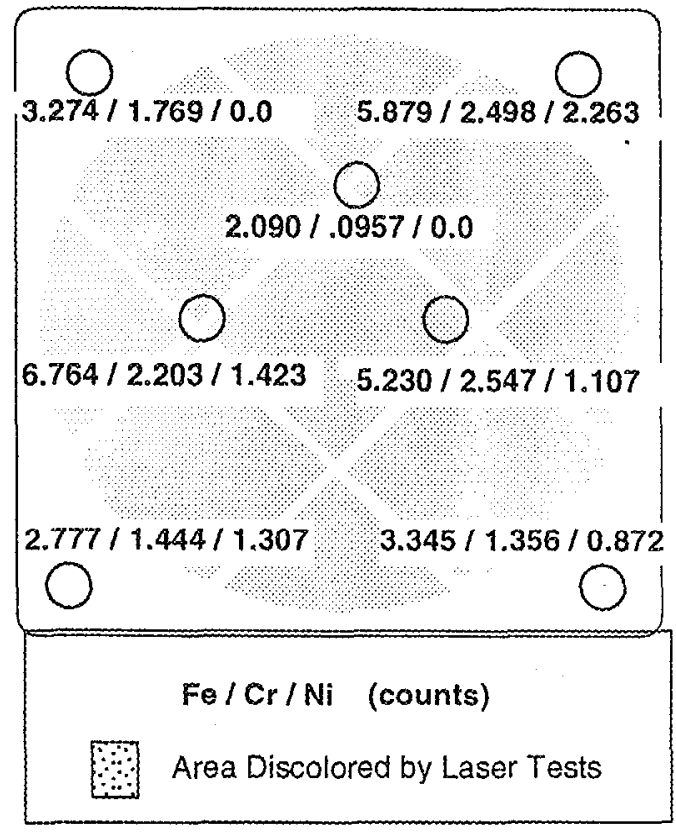

Figure 8: Map of the SS concentration on the fluoropolymer witness sheet from the final SS prototype test at $8.8 \mathrm{~kJ}$.. SS concentration, measured by XRF.
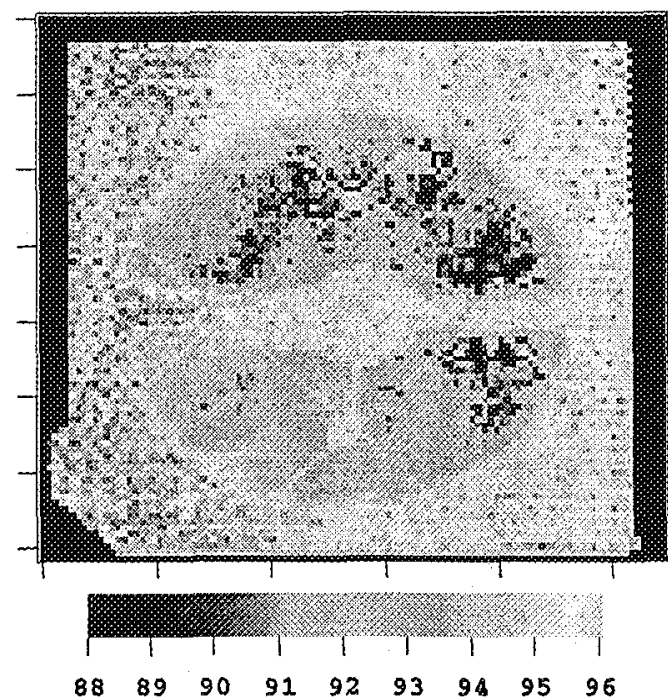

$\%$ Transmi $\approx$ Iion

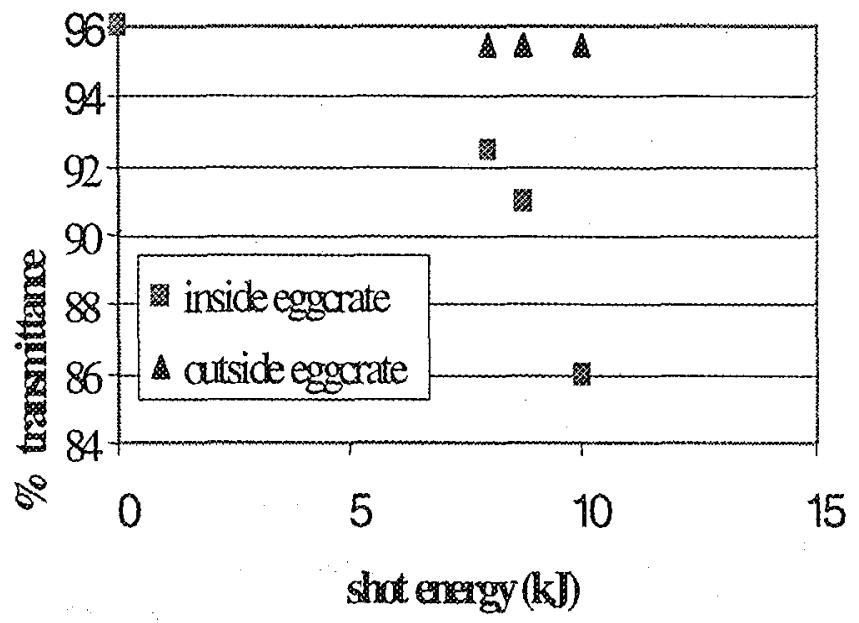

Figure 9: Transmittance through the fluoropolymer witness sheets from the SS prototype tests: a) map of the fluoropolymer witness sheet from the final SS prototype test at $8.8 \mathrm{~kJ}$ and b) as a function of shot energy and position. Transmittance inside the beam footprint ("inside eggcrate") is a strong function of shot energy due to the synergy of fluoropolymer film damage and SS contamination. Outside the beam footprint, the transmittance loss is independent of shot energy. The initial transmittance shown at $0 \mathrm{~kJ}$ shot energy includes surface reflection losses. 


\section{REFERENCES}

${ }^{1}$ P. Wegner, et al, "Erequency converter development for the National Ignition Facility," Solid State Lasers for Application to Inertial Confinement Fusion Third International Conference, June 7 - 12, 1998, Monterey, California.

${ }^{2}$ A. Burnham et al, "Constraints on Target Chamber First Wall and Target Designs that will Enable NIF Debris Shields to Survive," Solid State Lasers for Application to Inertial Confinement Fusion Third International Conference, June 7 - 12, 1998, Monterey, California.

${ }^{3}$ A. Anderson, R. Managan, M. Tobin, and P. Peterson, "X-ray Emission from National Ignition Facility Indirect Drive Targets," Fusion Technology, 30, 425-430 (1996).

${ }^{4}$ R. Tokheim, L. Seaman, T. Cooper, B. Lew, D. Curran, J. Sanchez, A. Anderson, M. Tobin, "Calculating the shrapnel generation and subsequent damage to first wall and optics components for the National Ignition Facility," Fusion Technology 20, 745-751 (1996).

${ }^{5}$ A. Burnham, M. Tobin, A. Anderson, E. Hone, K. Scullion, D. Milldam, M. Evans, F. Rainer, M. Gerassimenko, "Development and Evaluation of First Wall Materials for the National Ignition Facility," Fusion Technology 20, 730-735 (1996).

${ }^{6}$ A. Anderson, A. Burnham, M. Tobin, P. Peterson, "Modeling and Experiments of X-ray Ablation of National Ignition Facility First Wall Materials," Fusion Technology 20, 757-763 (1996).

${ }^{7}$ A. Rubenchik, et al, "Thin Film Contamination Effects on Laser Induced Damage of Fused Silica Surfaces at 355 nm," Solid State Lasers for Application to Inertial Confinement Fusion Third International Conference, June 7 12, 1998, Monterey, California.

${ }^{8}$ R. Rainer, A. Burnham, D. Milam, and R. Turner, "Lifetime of contaminated target chamber optics," LaserInduced Damage in Optical Materials: 1996, SPIE vol. 2966, 463-473 (1997).

${ }^{9}$ F. Genin, K. Michlitsch, J. Furr, M. Kozlowski, P. Krulevitch, "Laser-induced damage of fused silica at 355 and $1064 \mathrm{~nm}$ initiated at aluminum contamination particles on the surface," Laser-Induced Damage in Optical Materials: 1996, SPIE vol. 2966, 126-138 (1997).

${ }^{10}$ M. Norton, J.E. Murray, C. Boley, D. Milam, W. Sell, M. Feit, A. Rubenchik,"Development of Long-Lifetime, Low-Contamination Beam Dumps for NIF," Solid State Lasers for Application to Inertial Confinement Fusion, Second Annual International Conference, October 22 - 25, 1996, Paris, France.

${ }^{11}$ M. Norton, et al, "Long-Lifetime, Low-Contamination Metal Beam Dumps for NIF Spatial Filters," Solid State Lasers for Application to Inertial Confinement Fusion Third International Conference, June 7 - 12, 1998, Monterey, California.

${ }^{12}$ R. Sacks, personal communication 